\title{
Food Packaging Technology and its Emerging Trends: A Review
}

\author{
Anjum Ayoub*, Fozia Hameed and Julie D. Bandral \\ Division of Food science and Technology SKUAST Chatha Jammu - 180009, India \\ *Corresponding author
}

\section{A B S T R A C T}

\begin{tabular}{|l|}
\hline Ke y w or d s \\
$\begin{array}{l}\text { Food Packaging, } \\
\text { Flavors, Detectors, } \\
\text { Quality }\end{array}$ \\
\hline Article Info \\
\hline $\begin{array}{l}\text { Accepted: } \\
\text { 24 September } 2018 \\
\text { Available Online: } \\
\text { 10 October } 2018\end{array}$ \\
\hline
\end{tabular}

\section{Introduction}

The demand for minimum processed, easily prepared and ready-to-eat 'fresh' food products, worldwide food trade, and distribution from centralized processing pose major challenges for food safety and quality. The conventional methods of preservation like refrigeration, adding preservatives etc. are some of the methods but they might have side effects on environment like refrigeration on ozone layer, and on consumers like preservatives affects the health (Ayoub et al., 2017). Recent food-borne microbial outbreaks are driving a search for innovative ways to inhibit microbial growth in the foods while maintaining quality, freshness, and safety. One option is to use packaging to give an multiplied margin of safety and quality. The next generation of food packaging may include materials with antimicrobial properties. These packaging technologies could play a role in enhancing shelf-life of foods and minify the risk from pathogens. Antimicrobial polymers may find use in other food contact use as well.

Food and beverage packaging comprises 55\% to $65 \%$ of the $\$ 130$ billion value of packaging in the United States (Brody, 2008). Food processing and packaging industries spend an estimated $15 \%$ of the total variable costs on packaging materials (Esse, 2002). Industrial processing of food, reduced 
consumption of animal protein, importation of raw materials and ingredients to be converted in the United States, and insufficiency of time to select/prepare food from fresh ingredients have increased innovation in food and beverage packaging. The continued quest for innovation in food and beverage packaging is largely driven by consumer needs and demands influenced by changing global trends, such as enhanced life expectancy, less organizations investing in food production and distribution (Lord, 2008), and regionally ample and diverse food supply. The use of food packaging is a socioeconomic indicator of enhanced expending ability of the population or the overall domestic product as well as regional (rural as opposed to urban) food accessibility.

\section{The expanded roles of food and beverage packaging}

The principal function of packaging is protection and preservation from external contamination (Robertson., 2006). This function involves retardation of deterioration, extension of shelf life, and maintenance of quality and safety of packaged food. Packaging protects food from environmental influences such as heat, light, the presence or absence of moisture, oxygen, pressure, enzymes, spurious odors, microorganisms, insects, dirt and dust particles, gaseous emissions, and so on. All of these cause deterioration of foods and beverages (Marsh and Bugusu, 2007). Prolonging shelf life involves retardation of enzymatic, microbial, and biochemical reactions through various strategies such as temperature control; moisture control; addition of chemicals such as salt, sugar, carbon dioxide, or natural acids; removal of oxygen; or a combination of these with effective packaging (Robertson, 2006). Precise integration of the product, process, package, and distribution is critical to avoid recontamination. The ideal packaging material should be inert and resistant to hazards and should not allow molecular transfer from or to packaging materials (Robertson, 2006).

Other major functions of packaging include containment, convenience, marketing, and communication. Containment involves ensuring that a product is not intentionally spilled or dispersed. The communication function serves as the link between consumer and food processor. It contains mandatory information such as weight, source, ingredients, and now, nutritional value and cautions for use required by law. Product promotion or marketing by companies is achieved through the packages at the point of purchase (Kotler and Keller, 2006). Secondary functions of increasing importance include traceability, tamper indication, and portion control (Marsh and Bugusu, 2007). New tracking systems enable tracking of packages though the food supply chain from source to disposal. Packages are imprinted with a universal product code to facilitate checkout and distribution control. More recent innovations used include surface variations sensed by finger tips and palms, sound/music or verbal messages, and aromas emitted as part of an active packaging spectrum (Landau 2007). Gloss, matte, holograms, diffraction patterns, and flashing lights are also used.

\section{Types of packaging}

\section{Active packaging}

Active packaging systems are developed with the goal of extending shelf life for foods and increasing the period of time that the food is high quality. Active packaging technologies include some physical, chemical, or biological action which changes interactions between a package, product, and/or headspace of the package in order to get a desired outcome (Yam et al., 2005). The most common active systems scavenge oxygen from the package or 
the product and may even be activated by an outside source such as UV light (Gander, 2007). Active packaging is typically found in two types of systems; sachets and pads which are placed inside of packages, and active ingredients that are incorporated directly into packaging materials.

\section{Active packaging: sachets and pads}

In order to absorb or emit gases to a package or headspace, sachets and pads are very commonly used. Sachets were developed in the late $1970 \mathrm{~s}$ in Japan. For oxygen scavenging, the sachets essentially utilize the process of rusting, or the oxidation of iron compounds in the presence of oxygen and water. Oxygen scavengers can also be made based on enzyme technology. Oxygen absorbers are usually made of powdered iron or ascorbic acid. Iron based scavengers typically do not pass the metal detector inspections on most packaging lines, and in these incidences ascorbic acid is advantageous. Oxygen absorbers in sachets are commonly found in meat and poultry products, coffee, pizzas, baked goods and dried foods. Sachets that absorb carbon dioxide along with oxygen are also available and are most commonly found in roasted or ground coffee packages. Some sachets are capable of emitting ethanol as an antimicrobial agent to extend the shelf life of high moisture bakery products. Drip absorbent pads may be used in packages containing meats that are likely to leak after temperature fluctuations. These pads prevent the growth of molds or bacteria by absorbing water into super-absorbent polymer granules placed between two layers of micro porous non-woven polymer. Although sachets work well in many applications, they are not appropriate for every situation. Sachets cannot be used in liquid foods. They may not be used in a package made of flexible film, as the film will cling to the sachet and prevent it from performing its function. Sachets have the risk of accidental ingestion by consumers and this may account for their limited commercial success in North America and Europe (Yam et al., 2005).

\section{Active packaging: Materials containing active components}

More recent attempts at active scavenging have focused on incorporating the scavenger into the packaging material itself. This method has potential for use in polyethylene terephthalate (PETE) bottles and can be included in many plastic containers and closures. Adding scavengers to the plastic rather than a sachet can save many problems. For example, in a packaging film that is tight fitting such as a cheese pack, a sachet to absorb oxygen cannot be used because the tight fitting film would stifle its functionality. Incorporating oxygen absorbing materials into the plastic components of the packaging material could be more efficient. One way in which oxygen absorbers are being incorporated into plastic materials is the use of a polymer based absorber that is coextruded in various packaging structures. The oxygen absorber is activated via UV light so that the scavenging capacity is not exhausted before the end of the product shelf life (Anonymous, 2007). Some systems developed thus far use iron based chemistry in their packaging material. Flavor absorbers are also being used in active packaging (Robertson, 2006). It has been known for decades that packaging materials can scalp or absorb flavors from foods such as fruit juices. Scalping is now being used in a positive way to absorb unwanted flavors and odors.

Active packaging: Anti-microbial systems for food packaging

An exciting innovation in active packaging is the potential for the controlled release of 
antimicrobials from packaging materials. Antimicrobials incorporated in packaging materials could extend shelf live by preventing bacterial growth and spoilage. In one system, known as "BioSwitch" (De Jong et al., 2005), an antimicrobial is released on command when bacterial growth occurs. The basic concept is that a change in the environment such as $\mathrm{pH}$, temperature, or UV light occurs and the antimicrobial responds accordingly. The external stimulus results in a release of the antimicrobial component of the package. In this system, the antimicrobial is released on command, and the system is active only at specific conditions. This system could potentially increase the stability and specificity of preservation and reduce the amount of chemicals needed in foods. A common example of release on command antimicrobials in food packaging is the inclusion of polysaccharide particles that encapsulate antimicrobial compounds. Many bacteria will digest polysaccharide when they grow, and so if a bacterial contamination occurs, the growth of bacteria will release the antimicrobial compounds and should inhibit subsequent microbial growth.

The principles behind active packaging are based either on the intrinsic properties of the polymer used as packaging material itself or on the introduction (inclusion, entrapment etc.) of specific substances inside the polymer (Gontard, 2000). The intrinsic properties of the polymer can give rise to the active function next to, e.g., the intentional grafting of an active group or through the introduction of an active monomer inside the polymer chain. An active agent can be incorporated inside the packaging material or onto its surface, in multilayer structures or in particular elements associated with the packaging such as sachets, labels or bottle caps.

The nature of the active agents that can be added is very diverse (organic acids, enzymes, bacteriocins, fungicides, natural extracts, ions, ethanol etc.) as well as the nature of the materials into which they are included such as papers, plastics, metals or combinations of these materials. The active systems can be placed outside the primary packaging, in between different parts of the primary packaging or inside the primary packaging. In this last case, the systems can be in contact only with the atmosphere surrounding the food, in contact with the food surface or placed inside the food itself (for liquid foods). This diversity accounts for the innovation potential in this field but it also represents a real challenge for the safety assessment.

Active packaging can be classified into two main types: non-migratory active packaging acting without intentional migration, and active releasing packaging allowing a controlled migration of non-volatile agents or an emission of volatile compounds in the atmosphere surrounding the food Nonmigratory active packaging is a packaging which elicits a desirable response from food systems without the active component migrating from the packaging into the food. The most well-known examples of nonmigratory active packaging are moisture absorbers, mostly based on the adsorption of water by a zeolite, cellulose and their derivatives etc. The tendency in the market of moisture absorbers systems is to introduce the absorbing substances inside the packaging material in order to make the active system invisible for the consumer such as, e.g., absorbing trays for fresh meat or fish.

Other well-known active packaging systems are oxygen absorbers, mostly based on iron oxidation but they can also be based on ascorbic acid or catechol oxidation, on enzymatic catalysis as well as on many other reactions. The development of oxygen scavenging systems was first based on selfadhesive labels, others adhesive devices or 
loose sachets to be included in the packaging with the food. A second concept, developed later, was based on the design of active substances for being included in the packaging material itself, using monolayer or multilayer materials or reactive closures liners for bottles and jars (Rooney, 2005). Ethylene scavengers, based on various re-actions, are extensively used to slow down the maturation rate of climacteric fruits, a crucial point for importexport of fresh fruits and vegetables. Another example of non-migratory packaging is the antimicrobial packaging based on the entrapment in a silicate network of silver ions, a widely marketed antimicrobial agent. Nevertheless, even food con-tact antimicrobial systems with an assumed non-intended migration (e.g. silver or silver based systems, other immobilized or grafted biocides), are known to exhibit some degree of migration. Thus, there is a strong need to better understand the active agent principles and mechanisms as well as to optimize their use in order to design active pack-aging elements that

Are sufficiently effective and reduce detrimental side effects and Permit an accurate, knowledge-based, assessment of potential risks. It is clear from the existing literature in the challenging field of antimicrobial packaging that research results on antimicrobial systems are often not reproducible or even contradictory, i.e. the case of chitosan or chitosan based systems of which biocide phenomenology and the optimum efficiency have just recently been understood on the basis of the positive migration of glucosamine fractions (Fernandez-Saiz et al., 2006) and related to food composition (Fernandes et al., 2008). It should be mentioned that an extensive research is underway on in-package enzymatic processing and non-migratory antimicrobial packaging, including the grafting of active agents onto the polymer surface (Goddard et al., 2007). These agents can be, e.g., antimicrobials, antioxidants or enzymes that can act either on the surface of a solid food or in the bulk of liquid foods.

In the field of active releasing packaging, one of the best-known products is an ethanol releaser which is able to slow down mould growth and thus increasing the shelf-life of bakery products. Water vapour releasing sachets are a key element of successful innovative packaging for ready-to-cook fresh vegetables. Combined with a valve placed onto the plastic pouch, they permit to cook fresh vegetables in a microwave oven and to obtain, in only a few minutes, a freshly cooked meal with improved organoleptic and nutritional quality. Sulphur dioxide releaser packaging is extensively used for preserving grapes from mould development. Some commercial products are based on the reaction of calcium sulphite with moisture, while others are based on metabisulphite hydrolysis. In these cases, one of the breakdown products, originating from the reaction with moisture, is the active agent.

Another example of active releasing materials is a plastic film commercially available in Japan, containing allyl isothiocyanate (AITC), a strong antimicrobial substance extracted from mustard or wasabi. AITC is entrapped in cyclodextrins for protecting the volatile active agent from being thermally degraded during extrusion. When exposed to high moisture conditions after the packaging of the food product, cyclodextrins have the ability to change in structure and to release the antimicrobial agent in the atmosphere surrounding the food (Lee, 2005).

Research in the area of antimicrobial food packaging materials has significantly increased during recent few years as an alternative method for controlling microbial contamination of foods by the incorporation of 
antimicrobial substances in or coated onto the packaging materials (Benarfa et al., 2007). Much research is devoted to the design of antimicrobial packaging containing natural volatile antimicrobial agents for specific or broad microbial inhibition depending on the nature of the agents used or on their concentration. Different types of antimicrobial delivery systems and packaging material food combinations are developed to maximize the efficacy of the system (Gontard, 2007).

\section{Intelligent packaging systems}

Intelligent packaging systems exist to monitor certain aspects of a food product and report information to the consumer. The purpose of the intelligent system could be to improve the quality or value of a product, to provide more convenience, or to provide tamper or theft resistance (Robertson, 2006). Intelligent packaging can report the conditions on the outside of the package, or directly measure the quality of the food product inside the package. In order to measure product quality within the package, there must be direct contact between the food product or headspace and the quality marker. In the end, an intelligent system should help the consumer in the decision making process to extend shelf life, enhance safety, improve quality, provide information, and warn of possible problems. Intelligent packaging is a great tool for monitoring possible abuse that has taken place during the food supply chain. Intelligent packaging may also be able to tell a consumer when a package has been tampered with. There is currently work being developed with labels or seals that are transparent until a package is opened. Once the package is tampered with, the label or seal will undergo a permanent color change and may even spell out "opened" or "stop". Perhaps intelligent packaging will be able to inform a consumer of an event that occurred such as package tampering that may save their life.

\section{Intelligent packaging: Time-Temperature Indicators (TTIs)}

The intelligent packaging design that is leading the way in packaging technology is the time temperature indicator (TTI). The TTI is useful because it can tell the consumer when foods have been temperature abused. If a food is exposed to a higher temperature recommended, the quality of the food can deteriorate much quicker. A TTI can be placed on shipping containers or individual packages as a small self adhesive label, and an irreversible change, like a color change, will result when the TTI experiences abusive conditions. TTIs are particularly useful with chilled or frozen foods, where the cold storage during transportation and distribution are important for food quality and safety. TTIs are also used as freshness indicators for estimating the shelf life of perishable products. A TTI technology known as Time strip is currently being employed by Nestle in their food service products in the UK (Anonymous, 2007). The Time strip uses a steady diffusion of liquid through a membrane to measure the time that has elapsed at a particular temperature. This action can provide information about how long a product has been opened or in use. The Time strip is very useful for products like sauces that have to be refrigerated and used within a specific time period.

\section{Intelligent packaging: gas indicators}

Food is a complicated material to package because it is capable of respiration and therefore may change its own atmosphere when inside a package. The gas composition within a package can easily change due to the interaction of food with its environment. Gas indicators are a helpful means of monitoring the composition of gases inside a package by producing a change in the color of the indicator though a chemical or enzymatic reaction (de Jong et al., 2005). The indicators 
must be in direct contact with the gaseous environment directly surrounding the food in a package. Indicators are capable of signaling whether there is a gas leakage in the package, or they may be used to verify the efficiency of an oxygen scavenger. Gas indicators typically signal the presence or absence of oxygen and/or carbon dioxide. Oxygen in the air can cause oxidative rancidity, unwanted color changes in foods, and allow aerobic microbes to grow on foods. Oxygen indicators typically result in a color change when oxygen is present, and the presence of oxygen can indicate that the package has a leak or has been tampered with. Oxygen indicators can also indicate improper sealing of a package. Gas indicators are also being developed to detect water vapor, ethanol, and hydrogen sulfide.

\section{Intelligent packaging: Thermochromic inks}

Inks are available that are temperature sensitive and can change colors based on temperature. These inks can be printed onto packages or labels such that a message can be conveyed to the consumer based on the color of the ink they are seeing. Thermochromic inks can let a consumer know whether a package is too hot to touch, or cold enough drink. Thermochromic inks are becoming a popular technology for beverages (Robertson, 2006). The inks used can be adversely affected by UV light and temperatures over $121^{\circ} \mathrm{C}$, so consumers should not fully rely on the inks message when it comes to deciding the proper time to consume a food.

\section{Biosensors for pathogen or toxin identification}

Food borne pathogens are of great concern to the food industry and many consumers have become increasingly aware of this problem. The need to rapidly and accurately detect small amounts of pathogen or toxins in food is an essential step in keeping the consumer safe. A biosensor is an analytical device used to detect a substance, in this case a pathogen, and then transmit this information into some sort of signal that is quantifiable. An intelligent system in the works aims attaches antibodies to a plastic packaging surface to detect pathogens or toxins (Yam et al., 2005). If the antibodies come into contact with the target pathogen, the packaging material would display a visual cue to alert the consumer. This intelligent system would only be useful when foods were contaminated with very high concentrations of pathogen or toxin. In reality, a consumer could get ill from just small concentrations of pathogen or toxin and this intelligent system could give the consumer a false sense of security. Also, this system would work only to detect pathogens or toxin on the surface of a food product, and would not alert consumers of the dangerous substances that could potentially be distributed throughout the product. This system has a long way to go before it becomes commercially available.

\section{Microwave doneness indicators}

Producers of microwave ovenable foods are anxiously anticipating microwave doneness indicators (MDIs). These indicators would be able to detect the readiness of foods that are heating in microwave ovens and signal to consumers when foods are safe to eat. The biggest challenge in this field at the moment is the ability to evenly heat foods in the microwave so that there is a defined stage in which a food could be called safe to eat. Currently, foods heat nonuniformly, and hot spots occur throughout the food. These hot spots would trigger a doneness indicator while cooler regions would not have reached acceptable cooking temperatures. An ideal MDI would be located on the lid or dome of the microwave container so that the consumer could easily see the visual indicator for 
doneness (Robertson, 2006). This would be functional as a food is heated in the microwave and the space above the food would heat and transfer to the lid. The relationship between the temperature of the food and the temperature of the lid would be the basis of the indicator system. It would be important that the indicator not give false reading because the device itself heats in the microwave. The indicator must also be viewable by the consumer without having to open the microwave. As of yet, MDIs do not exist commercially, but their arrival is much anticipated.

\section{Radio Frequency Identification (RFID)}

It is believed that tomorrows food packages will certainly include radio frequency identification (RFID) tags (Gander, 2007). RFID tags are an advanced form of data information carrier that can identify and trace a product. They are currently used for tracking expensive items and livestock (Anonymous, 2007). In a typical system, a reader emits a radio signal to capture data from an RFID tag.
The data is then passed to a computer for analysis. RFID tags contain a microchip connected to a tiny antenna. This allows for the tags to be read for a range of 100 feet or more in more expensive tags, to 15 feet in less expensive tags (Yam et al., 2005). The RFID tag could offer much more than a conventional bar-code. In contrast to a bar-code, RFID does not need to be in a direct line of sight to be recognized by a scanner. This could revolutionize the way check-out works at a grocery store. Many RFID tags can be read simultaneously at a rapid rate. RFID tags could also store information such as temperature and relative humidity data, nutritional information and cooking instructions. They could be integrated with a time-temperature indicator or a biosensor to carry time-temperature information or microbiological data (Yam et al., 2005). RFID technology in the food system is still in the early stages. Simple applications like tracking and identification are the focus of most food science matters, and these must be perfected before more complex applications can come to light.

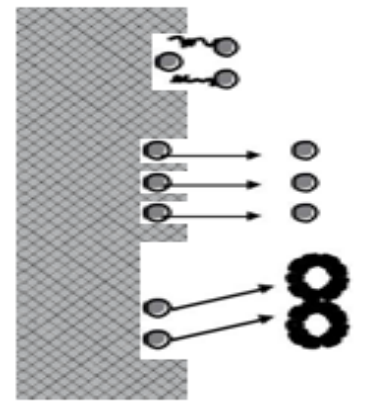

Non Migratory Active FCM:

- Effect without intentional migration (covalent grafting or immobilisation of active functions)

Active Releasing FCM:

- contact effect for controlled migration of nonvolatile active agents

- controlled/triggered emission of active volatile compounds into heads pace atmosphere surrounding food

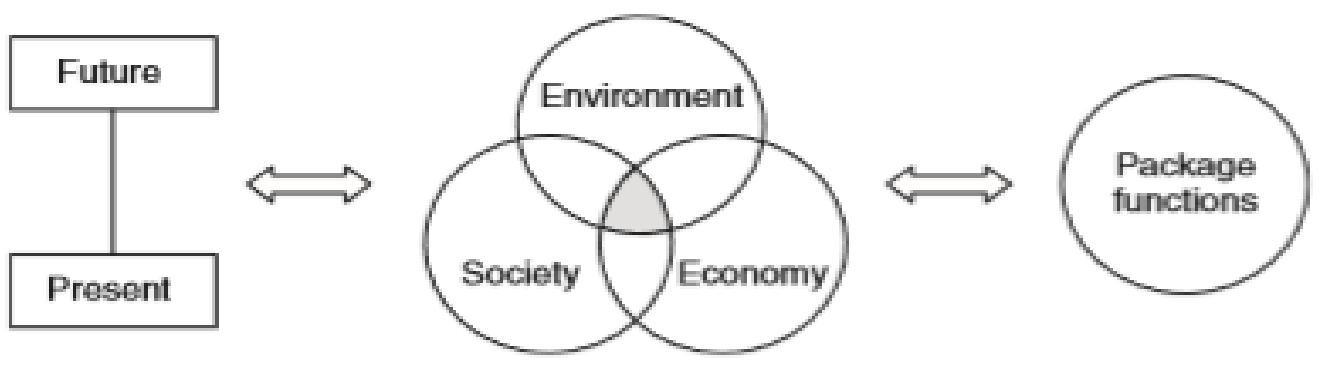




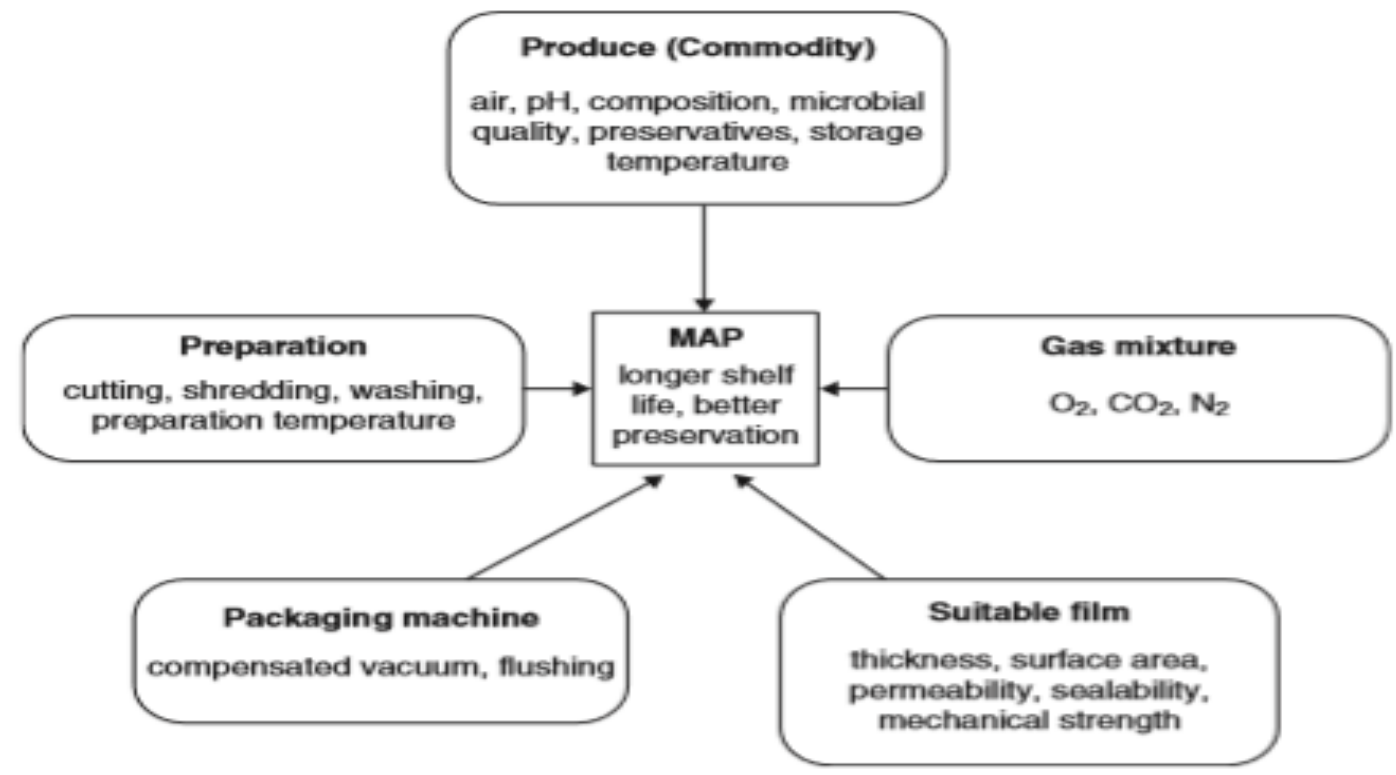

\section{Freshness indicators}

According to Huis in't Veld, the changes taking place in freeze-chilled food products can be categorized as Microbiological growth and metabolism leading to $\mathrm{pH}$ changes, formation of toxic substances, off-odors, offflavors, gas, and/or slime formation,

Oxidation of lipids and pigments resulting in undesirable flavors in terms of rancidity, formation of chemicals with adverse biological reactions, or discoloration. The focus of these freshness indicators is on intelligent concepts indicating the changes associated with both categories. A freshness indicator directly determines the quality of food product using either metabolites from microbial growth or chemicals from lipid oxidation as "information" to monitor a status of the freshness of food product.

\section{Enzyme-based time-temperature indicator}

The Check Point ${ }^{\circledR}$ I is based on enzymatic hydrolysis of a lipid substrate. Prior to activation the indicator comprises two separate compartments, in the form of plastic mini-pouches. One compartment is filled with an aqueous solution of a lipolytic enzyme (i.e., pancreatic lipase). The other contains the lipid substrate incorporated in a pulverized polyvinylchloride (PVC) carrier, which is suspended in an aqueous phase and a $\mathrm{pH}$ indicator mix. Glycerine tricapronate (tricaproin), tripelargonin, tributyrin, and mixed esters of polyvalent alcohols and organic acids are included in substrates (Blixt, 1977; Agerhem, 1981). Hydrolysis of the substrate causes acid release and the $\mathrm{pH}$ drop is translated into a color change, initially deep green to bright yellow, orange and finally red.

Emerging technologies to improve the sustainability of the food supply system

In recent years there has been an increasing demand to improve the sustainability of the food supply system. New packaging technologies can play an important role in meeting this demand. The Sustainable Packaging Coalition, a leading organization for sustainable packaging, defines sustainable packaging as a target vision for creating 'a world where all packaging is sourced responsibly, designed to be effective and safe 
throughout its life cycle, meets market criteria for performance and cost, is made entirely using renewable energy, and once used is recycled efficiently to provide a valuable resource for subsequent generations' (Green Blue, 2005). Sustainable packaging has been proposed as a holistic concept to develop packaging with three interrelated components (Lee et al., 2008). The first component is related to time and perpetuality. Sustainable packaging is aimed at not only meeting the needs of the present generation, but also the needs of future generations.

It requires a cradle to cradle flow of packaging materials in which materials can be used repeatedly without depleting resources. The second component is related to striking a health balance to meet the needs of the environment, society and the economy - a packaging system is not truly sustainable until all three of these are addressed in an equitable manner. For example, a packaging system with the sole purpose of maximizing profits is irresponsible if it fails to address the needs of the environment and society. Similarly, a packaging system with the sole purpose of minimizing the negative impacts to the environment is unrealistic if it fails to address the needs of society and the economy.

The third component is related to packaging functions (containment, protection, convenience and communication). Unless a package can perform some useful functions, the justification for its existence is questionable. For example, a package may be considered environmentally friendly because it is biodegradable; however, if it fails to protect the product, the product is likely to be discarded and not used by the consumer. Packaging functions are, unfortunately, largely overlooked in the literature when sustainable

Figure shows Conceptual framework of sustainable packaging.

\section{Modified atmosphere packaging (MAP)}

Modified atmosphere packaging (MAP) is a widely used modern packaging technology used to extend the shelf life of minimally processed fresh produce. As the name suggests, MAP of fresh produce involves packaging produce in polymer films that maintain a commodity-specific modified atmosphere such as reduced oxygen levels and elevated carbon dioxide levels (Kader and Saltveit, 2003; Yam and Lee, 1995). The mixture of gases inside a package for fresh produce can be different from that in the normal atmosphere outside the package, so long as the total pressure inside and outside the package is equilibrated. In order to maintain this equilibrium, a number of parameters must be taken into account, including the respiration rate and mass of the product in question, the thickness and surface area of the polymer fi $1 \mathrm{~m}$, the gas transmission rates through the film, the initial free volume and atmospheric composition within the package, and external environmental factors such as temperature and relative humidity (Fig.) (Yam and Lee, 1995; Kader and Saltveit, 2003; Mannapperuma and Singh, 1994). Metallocene polymerization, blending, lamination, and coextrusion are examples of emerging technologies which are used to deal with the permeability of the fi $\mathrm{lm}$ and its physical properties such as optical properties and seal bonding (Brandenburg and Zagory, 2009; Acosta et al., 2011).

Modified atmosphere can be created in two ways:

Passive MAP: The produce respiration rate is matched with films of appropriate permeability to generate an atmosphere that passively evolves as a result of consumption of oxygen and evolution of carbon dioxide due to the respiration. Films of adequate gas permeability must be chosen such that oxygen 
enters the package at a rate offset by the consumption of oxygen by respiration of the fruit or vegetable in question. Similarly, carbon dioxide must be vented from the package at a rate offset by the production of carbon dioxide as a result of produce respiration. This modified atmosphere should ideally be established rapidly, without creating injuriously high levels of carbon dioxide or low

Figure Shows Parameters to be considered for designing MAP of fresh produce

Active MAP: Active MAP is performed in two ways. In the first method, the package is evacuated and then flushed with the desired gas mixture. In the second method, the desired gas mixture is continuously flowed into the package through a lance, replacing the existing air. Absorbers or adsorbers may be used within the package to scavenge oxygen, carbon dioxide or even ethylene, helping to maintain an atmosphere that promotes extended shelf life. Active MAP for fresh produce is an essential method for high oxygen MAP.

Low oxygen MAP: The most commonly applied MAP for fresh produce is low oxygen MAP, where the oxygen concentration inside the package is lowered to $1-10 \%$ instead of the usual $21 \%$ in air. These low concentrations of oxygen in the package act to suppress produce respiration rates. Low oxygen MAP also involves increasing the carbon dioxide concentration inside the package to above the usual $0.03 \%$ in air. Elevated carbon dioxide levels also help to reduce produce respiration rates. The combination of reduced oxygen and elevated carbon dioxide levels reduces the respiration rates of fresh produce and decreases ethylene production, thereby delaying ripening, preventing softening of texture, maintaining freshness, and ultimately extending the shelf life of the product.
The use of low $\mathrm{O}_{2}$ MAP for the packaging of various fresh produce commodities is already well established. For most fresh produce a typical gas mixture for MAP contains oxygen concentrations in the range of $1-10 \%$ and carbon dioxide concentrations in the range of 1-20\%. For example, a packet of mixed salad has a typical equilibrium modified atmosphere consisting of $5 \%$ oxygen, $15 \%$ carbon dioxide, and $80 \%$ nitrogen. Specific gas mixture compositions for a variety of fruits and vegetables can be found in the literature (Yam and Lee, 1995; Sandhya, 2010).

High oxygen MAP: Research has also been carried out on the application of high oxygen MAP to the packaging of fresh produce. High oxygen MAP involves using oxygen concentrations greater than $40 \%$, and usually between $70 \%$ and $95 \%$. High oxygen MAP has been found to be effective in inhibiting enzymatic discoloration, preventing anaerobic fermentation reactions and inhibiting microbial growth. Studies have also shown that exposure to high oxygen alone (80-90\% oxygen, balance nitrogen) did not inhibit microbial growth but caused a variable reduction in growth rate of some tested microorganisms at low temperature and prolonged the lag phase of growth (Jacxsens et al., 2001; Conesa et al., 2007).

Several factors have so far prevented the commercialization of high oxygen MAP for fresh produce: a lack of understanding of the biological mechanisms involved in inhibiting microbial growth and enzymatic browning; the effect of the MAP on the respiratory activity and nutritional quality of produce; and concerns about the safety of packaging produce in high oxygen MAP. Concentrations of oxygen above $25 \%$ are considered to be explosive and hence special precautions need to be taken when packaging produce in high oxygen MAP. 


\section{Active packaging}

The conventional function of a package is to protect the food from the external environment, inhibiting chemical and physical changes. Increased consumer demand for minimally processed foods and foods without additives, along with increased consumer concern about food safety, have led the food packaging industry to search for an innovative packaging technology where the package contributes to maintaining the quality and safety of the product in addition to simply acting as a protective barrier. Active packaging is an emerging area in which most of these requirements can be met. With the introduction of the concept of 'active packaging', the function of the package has changed from passive protection to active contribution to maintaining the quality and safety of the food.

\section{Absorbing system}

Fresh produce continues to respire even after harvest, producing moisture and carbon dioxide:

$\mathrm{C}_{6} \mathrm{H}_{12} \mathrm{O}_{6}+6 \mathrm{O}_{2}=6 \mathrm{CO}_{2}+6 \mathrm{H}_{2} \mathrm{O}+$ heat

The transpiration of moisture from respiration and the humidity differential between the surface of the produce and the environment leads to the accumulation of moisture vapor inside the package, which may saturate the headspace and condense on the internal surface of the package and on the surface of the produce. The condensed moisture may act as a site for microbial growth and decay of the product. The controlled absorption of moisture from the package headspace by a moisture absorber can maintain unsaturated water activity at the correct level inside the package. Different types of moisture absorbers are available in the market depending on the specific requirements of the application, for example, $\mathrm{CaCl}_{2}, \mathrm{KCl}$ and sorbitol for fast absorption, and bentonite for slow absorption. A combination of different absorbers can be used to achieve a particular absorption rate (Mahajan et al., 2008).

Carbon dioxide, mainly produced by the respiration of fresh fruits and vegetables, can cause physiological stress in fresh produce if it is allowed to accumulate to excessive levels inside the package. The controlled removal of $\mathrm{CO}_{2}$ is therefore helpful in maintaining the quality of the product. The most commonly used $\mathrm{CO}_{2}$ absorbers are calcium hydroxide, activated charcoal, zeolite, and magnesium oxide. Because some level of oxygen is required for the normal metabolism of respiration in fresh produce, its removal by absorption is usually not attempted in a fresh produce package. In some cases, in order to achieve the optimal atmosphere as rapidly as possible, oxygen absorbers can be positioned inside the package as inserts in the form of a sachet, or as self-adhesive labels which are either placed inside the package or attached to the polymer fi $\operatorname{lm}$ (Charles et al., 2003).

\section{Releasing system}

There are some gas-phase molecules which are beneficial in maintaining the quality of fruits and vegetables and are often deliberately delivered inside the package so that they are available in the package headspace, for example, 1methylcyclopropene $\left(\mathrm{MCP}, \mathrm{C}_{4} \mathrm{H}_{6}\right)$, an ethylene antagonist and chlorine dioxide $\left(\mathrm{ClO}_{2}\right)$, a microcidal agent. Volatile antimicrobials are helpful in the preservation of the microbial quality of produce when delivered from antimicrobial sachets or films Exposure of fresh produce to ethylene generally leads to over-ripening and facilitates microbial growth, thus limiting the shelf life. The discovery of the ethylene inhibitor MCP offers another method of delaying the 
ripening and senescence of fruits and vegetables, thereby extending the shelf life. At concentration of $2.5 \mathrm{~nL} / \mathrm{L}$ to $1 \mu \mathrm{L} / \mathrm{L}, \mathrm{MCP}$ inhibits the effects of ethylene in a wide range of fruits, vegetables, and fl oriculture crops (Blankenship and Dole, 2003). The response of fruits and vegetables to $\mathrm{MCP}$ and its commercial applications are discussed in a number of review papers (Blankenship and Dole, 2003; Watkins, 2006).

The most common commercial method used for MCP treatment is the release of MCP gas from cyclodextrin powder. Moisture should be supplied as a trigger to release the gas from cyclodextrin into the room containing the fresh produce. Sachet and fi $\mathrm{lm}$ forms have been investigated for the release of MCP in the produce package (Lee et al., 2006; Hotchkiss et al., 2007).

\section{Antimicrobial packaging}

Antimicrobial packaging can usually be considered as a kind of active packaging involving the release of antimicrobial substances. Most available antimicrobial systems are based on migration of antimicrobials, although some systems exist which are based on the intrinsic antimicrobial properties of the contacting surface of the packaging material (Lee and Han, 2011). Indirect contact system does not allow the delivery of antimicrobials in liquid or solid phase, only volatile antimicrobials can work in the system. The migration or delivery of antimicrobials can occur thorough desorption (or evaporation) and gas-phase diffusion. The advantage of volatile antimicrobials is that they can readily penetrate irregular food surfaces through void spaces or channels. These advantages offered by an indirect contact antimicrobial packaging system have led many researchers to look for an effective method of incorporating volatile antimicrobials into a polymer matrix. The
$\mathrm{C}_{1} \mathrm{O}_{2}$-releasing packaging is one useful indirect system (Gontard and Guillaume, 2010).

\section{Edible coatings}

Traditionally, edible wax coatings have been applied to the fresh produce surface in order to improve appearance, reduce bruising during handling and shipping, reduce weight loss, and to provide a carrier for active compounds. Commodities commonly coated include apples, avocados, bell peppers, cantaloupes, cucumbers, eggplants, grapefruits, lemons, limes, melons, oranges, parsnips, passion fruit, peaches, pineapples, pumpkins, rutabagas, squash, sweet potatoes, tomatoes, turnips and yucca. The edible macromolecules used as the coating can be classified into polysaccharides, proteins, and lipids. Comprehensive information on the use of edible coatings on fresh produce can be found in Baldwin (1994). The physical properties of the coating and its permeability to moisture, oxygen, and carbon dioxide are important in realizing its beneficial effects. One recent trend is the development and use of edible coatings that can improve the safety and quality of fresh-cut produce. Edible coatings may contribute to extending the shelf life of fresh-cut produce by reducing moisture and solute migration, gas exchange, respiration and oxidative reaction rates, and by reducing or even suppressing physiological disorders (Rojas-Graü et al., 2009).

Innovative packaging includes active and intelligent packaging system. They offers very innovative opportunities for convenience, quality and food safety. Some experts rely that the next round of technology in packaging will contain nanotechnologies that will allow new compounds like gas scavengers and novel antimicrobials to be incorporated in packaging films. Due to the development of electronic devices that can be 
made inexpensively will also help drive the innovative direction of active and intelligent packaging. As our society continues to develop, the expectations of the consumers will continue to advance. The use of active and intelligent packaging will likely become more famous as numerous technologies make their way to the market. The innovate packaging in active and intelligent system will become more common place. Perhaps the active and intelligent packaging will replace the traditional packaging entirely. According to the (Gander, 2007) trend is towards less packaging, what will be there is more interactive. 2020 will see packs which moves or walks off the shelf.

\section{References}

Acosta M N, Ercoli D R, Goizueta G S, Lozano J E, Capiati N J (2011), 'Blends of PP/ PE co-octene for modified atmosphere packaging applications', Packaging Technology and Science, 24(4), 223-225.

Agerhem H., H.J. Nilsson. Substrate composition and use thereof. United States Patent Publication, US 4284719, 1981.

Anonymous. 2007. Smart packaging: coming to a store near you. Food Engineering \& Ingredients. 32: 20-23.

Ayoub, Anjum, S.A. Sofi, and Ashish Mohite. 2017. "Physico-Chemical Analysis of Fruit Juices by Using Self-Made Low Cost Portable Ohmic Heater." International Journal of Agriculture, Environment and Biotechnology 10 (6): 739.

Baldwin e a (1994), 'Edible coatings for fresh fruits and vegetables: past, present, and future', in Krochta J M, Baldwin E A and Nisperos-Carriedo $\mathrm{M} \mathrm{O}$, Edible Coatings and Films to Improve Food Quality, Boca Raton, FL: CRC Press, pp. 25-64.
Benarfa, A., Presiozi-Belloy, L., Chalier, P., and Gontard, N. (2007). Antimicrobial paper baser on soy protein isolate or modified starch coating including carvacrol and cinnamaldehyde. Journal of Agricultural and Food Chemistry, 55, $2155 \mathrm{e} 2162$.

Blankenship S M, Dole J M (2003), '1Methylcyclopropene: a review', Postharvest Biology and Technology, 28(1), 1-25.

Blixt, K.G., S.I.A. Tornmarck, R. Juhlin K.R. Salenstedt, M. Tiru. Enzymatic substrate composition adsorbed on a carrier. United States Patent Publication, US 4043871, 1977.

Brandenburg J S, Zagory D (2009), 'Modified and controlled atmosphere packaging technology and applications', in Yahia E M, Modified and Controlled Atmospheres for the Storage, Transportation, and Packaging of Horticultural Commodities, Boca Raton, FL: CRC Press, pp. 73-92.

Brody A. 2008. Packaging by the numbers. Food Tech., 62(2): 89-91.

Charles F, Sanchez J, Gontard N (2003), 'Active modified atmosphere packaging of fresh fruits and vegetables: modeling with tomatoes and oxygen absorber', Journal of Food Science, 68(5), 17361742.

Conesa A, Artes-Hernandez F, Geysen S, Nicolai B, Artes F (2007), 'High oxygen combined with high carbon dioxide improves microbial and sensory quality of fresh-cut peppers', Postharvest Biology and Technology, 43, 230-237.

De Jong, A.R., Boumans, H., Slaghek, T., Van Veen, J., Rijk, R. and Van Zandvoort, M. 2005. Active and intelligent packaging for food: is it the future? Food Additives \& Contaminants: Part A. 22: 975-979. 
Esse R. 2002. Flexible packaging end-use market analysis. Linthicum, Md.: Flexible Packaging Assn.

Fernandes, J., Tavaria, F., Soares, J., Ramos, O., Monteiro, M., Pintado, M., et al., (2008). Antimicrobial effects of chitosans and chito oligosaccharides, upon Staphylococcus aureus and Escherichia coli, in food model systems. Food Microbiology, 25, 922e928.

Fernandez-Saiz, P., Ocio, M. J., and Lagaron, J. M. (2006). Film-forming process and biocide assessment of high-molecularweight chitosan as determined by combined ATR-FTIR spectroscopy and antimicrobial assays. Biopolymers, 83(6), 577e583.

Gander, P. 2007. The smart money is on intelligent design. Food Manufacture Feb: xv-xvi.

Goddard, J. M., Talbert, J. N., and Hotchkiss, J. H. (2007). Covalent attachment of lactase to low-density polyethylene films. Journal of Food Science, 72(1).

Gontard N, Guillaume C (2010), 'Packaging and the shelf life of fruits and vegetables', in Robertson G L, Food Packaging and Shelf Life, Boca Raton, FL: CRC Press, pp. 297-315.

Gontard, N. (2000). In: N. Gontard (Ed.), Les Emballages Actifs. Paris, France: Tech $\&$ Doc Editions, Lavoisier.

Gontard, N. Antimicrobial paper based packaging. In: International antimicrobial in plastic and textile applications. Intertech PIRA conference. 27e26 June 2007, Prague, Czech Republic.

Greenblue (2005) Definition of Sustainable Packaging, Version 1.0, Sustainable Packaging Coalition, Pp. 1.

Hotchkiss J H, Watkins C B, sanchez D G (2007), 'Release of 1methylcyclopropene from heat-pressed polymer films', Journal of Food
Science, 72(5), E330-E334. Jacxsens L, Devlieghere F, Van der Steen C, Debevere J (2001), 'Effect of high oxygen modified atmosphere packaging on microbial growth and sensorial qualities of fresh-cut produce', International Journal of Food Microbiology, 71, 197-210.

Huis In't Veld, J.H.J. Microbial and biochemical spoilage of foods: An overview. International Journal of Food Microbiology, 33: 1-18, 1996.

Jacxsens L, Devlieghere F, Van der steen C, Debevere J (2001), 'Effect of high oxygen modified atmosphere packaging on microbial growth and sensorial qualities of fresh-cut produce', International Journal of Food Microbiology, 71, 197-210.

Kader A A, Saltveit M E (2003), 'Atmosphere modification', in Bartz J A and Brecht J $\mathrm{K}$, Postharvest Physiology and Pathology of Vegetables, New York: Marcel Dekker, pp. 229-246.

Kotler P, Keller K. 2006. Marketing management. $12^{\text {th }}$ ed. Upper Saddle River, N.J.: Pearson.729p.

Landau S. 2007. The future of flavor and odor release. In the future of caps and closures-latest innovations and new applications for caps and closures, Intertech Pira conference. 20-21 June 2007, Atlanta, Ga.

Lee $\mathrm{d} \mathrm{s}$, han $\mathrm{j} \mathrm{h}$ (2011), 'Antimicrobial packaging', in Zhang $\mathrm{H}$ Q, BarbosaCanovas G V, Balasubramaniam V M, Dunne C P, Farkas D F and Yuan J T C, Nonthermal Processing Technologies for Food, Chichester: Wiley-Blackwell, pp. 462-471.

Lee Y S, Beaudry R, Kim J N, Harte B R (2006), 'Development of a 1methylcyclopropene (1-MCP) sachet release system', Journal of Food Science, 71(1), C1-C6. 
Lee, D. S. (2005). Packaging containing natural antimicrobial or anti-oxidative agents. In J. H. Han (Ed.), Innovations in food packaging. Elsevier Academic Press.

Lee, D. S., Yam, K. L and Piergiovanni, L (2008) Food Packaging Science and Technology, Boca Raton, FL, CRC Press, 4-11, 596-597.

Lord JB. 2008. The food industry in the United States. In: Brody AL, Lord J, editors. Developing new food products for a changing market place.2nd ed. Boca Raton, Fla.:CRSPress.p1-23.

Mahajan P V, Rodrigues F A S, Motel A, Leonhard A (2008), 'Development of a moisture absorber for packaging of fresh mushrooms (Agaricus bisporous)', Postharvest Biology and Technology, 48(3), 408-414.

Mannapperuma J D, Singh R P (1994), 'Modeling of gas exchange in polymeric packages of fresh fruits and vegetables', in Singh R P and Olivera F A R, Minimal Processing of Foods and Process Optimization, Boca Raton, FL: CRC Press, pp. 437-458.

Marsh K, Bugusu B. 2007. Food packaging: roles, materials, and environmental issues. JFoodSci 72(3): R39-55.

Robertson G. 2006. Food packaging principles and practices. $2^{\text {nd }}$ ed. Boca Raton, Fla.: Taylor\&Francis. 545 Pp.
Robertson, G. L. 2006. Active and intelligent packaging. In Food packaging: principles and practice- 2nd ed. CRC Press, Boca Raton, Fl. Chap. 14.

Rojas-graü M A, Soliva-fortuny R, MartínBelloso O (2009), 'Edible coatings to incorporate active ingredients to freshcut fruits: a review', Trends in Food Science and Technology, 20, 438-447.

Rooney, M. (2005). Introduction to active food packaging technologies. In J. $\mathrm{H}$. Han (Ed.), Innovations in food packaging. Elsevier Academic Press.

Sandhya (2010), 'Modified atmosphere packaging of fresh produce: current status and future needs', LWT-Food Science and Technology, 43, 381-392.

Watkins C B (2006), 'The use of 1methylcyclopropene (1-MCP) on fruits and vegetables', Biotechnology Advances, 24(4), 389-409.

Yam K L, Leeds (1995), 'Design of modified atmosphere packaging for fresh produce', in Rooney M L, Active Food Packaging, London: Blackie Academic and Professional, pp. 55-73.

Yam, K. L., Takhistov, P. T., and Miltz, J. 2005. Intelligent packaging: concepts and applications. Journal of Food Science. 70: R1-R10.

\section{How to cite this article:}

Anjum Ayoub, Fozia Hameed and Julie D. Bandral. 2018. Food Packaging Technology and its Emerging Trends: A Review. Int.J.Curr.Microbiol.App.Sci. 7(10): 3363-3378. doi: https://doi.org/10.20546/ijcmas.2018.710.390 